\title{
On the Emergence of Tremor in Prodromal Parkinson's Disease
}

Conor Fearon MB PhD MRCPI ${ }^{1}$, Andrew J. Lees FRCP FRCP (Ed) FMedSci², John J. McKinley MB MMedSc FRCP (UK) ${ }^{3}$, Allan McCarthy MB MRCPI ${ }^{4}$, Shane Smyth MB $\mathrm{MRCPI}^{1}$, Michael Farrell MB FRCPath FRCPI FRCPC ${ }^{5}$ \& Timothy Lynch MB FRCPI FRCP ${ }^{1}$

${ }^{1}$ Centre for Brain Health, Dublin Neurological Institute at the Mater Misericordiae University Hospital, Dublin, Ireland

${ }^{2}$ Reta Lila Weston Institute of Neurological Studies University College London, London $U K$.

${ }^{3}$ Department of Neurology, Royal Victoria Hospital, Belfast, UK.

${ }^{4}$ Department of Neurology, Tallaght University Hospital, Dublin, Ireland

${ }^{5}$ Department of Neuropathology, Beaumont Hospital, Dublin, Ireland

Corresponding authors:

- Timothy Lynch, Centre for Brain Health, Dublin Neurological Institute at the Mater Misericordiae University Hospital, 57 Eccles Street, Dublin 7, tlynch@dni.ie

Keywords: Parkinson's Disease, tremor, yawning, dopamine

Word count: 3841 words

Abstract: 252 words

References: 79 


\section{Abstract}

Clinical, neuropathological and neuroimaging research suggests that pathological changes in Parkinson's disease (PD) start many years before the emergence of motor signs. Since disease-modifying treatments are likely to be most effective when initiated early in the disease process, there has been significant interest in characterizing prodromal PD. Some people with PD describe autonomic symptoms at the time of diagnosis suggesting that autonomic dysfunction is a common feature of prodromal PD. Furthermore, subtle motor signs may be present and emerge prior to the time of diagnosis. We present a series of patients who, in the prodromal phase of $P D$, experienced the emergence of tremor initially only while yawning or straining at stool and discuss how early involvement of autonomic brainstem nuclei could lead to these previously unreported phenomena. The hypothalamic paraventricular nucleus (PVN) plays a central role in autonomic control including bowel/bladder function, cardiovascular homeostasis and yawning and innervates multiple brainstem nuclei involved in autonomic functions (including brainstem reticular formation, locus ceruleus, dorsal raphe nucleus and motor nucleus of the vagus). The PVN is affected in PD and evidence from related phenomena suggest that the PVN could increase tremor either by increasing downstream cholinergic activity on brainstem nuclei such as the reticular formation or by stimulating the locus ceruleus to activate the cerebellothalamocortical network via the ventrolateral nucleus of the thalamus. Aberrant cholinergic/noradrenergic transmission between these brainstem nuclei early in PD could lead to tremor before the emergence of other parkinsonian signs, representing an early clinical clue to prodromal PD. 


\section{Introduction}

The diagnosis of Parkinson's disease (PD) is centered on the identification of a predominantly motor phenotype. Converging evidence from clinical, neuropathological and neuroimaging research, however, suggests that pathological changes in people with Parkinson's disease (PwP) start years before the emergence of core motor signs [1,2]. A recent hypothesis in PD is that alpha-synuclein may spread from the peripheral autonomic nervous system to lower brainstem nuclei and only thereafter to areas salient to movement [2-4]. In particular, a body-first subtype of PD has been recently described whereby multimodal imaging supports cardiac and colonic denervation which may occur in prodromal PD [5]. Hence, it is not surprising that PwP report autonomic symptoms at the time of diagnosis [6]. Since diseasemodifying treatments are likely to be most effective when initiated early in the disease process, there has been interest in identifying and characterising prodromal PD [7].

REM-sleep behavior disorder (RBD), the prototypical prodromal syndrome in PD, has complex pathophysiology involving GABAergic, glutamatergic and cholinergic mechanisms centered on a number of critical brainstem nuclei [8]. Post-mortem, animal and imaging studies suggest that cholinergic degeneration of the mesopontine tegmentum plays a central role in $\operatorname{RBD}[9,10]$. Other prodromal markers of PD are regulated by the autonomic nervous system and include constipation, orthostatic hypotension, urinary and erectile dysfunction [7]. In parallel, some cholinergic, serotoninergic and noradrenergic brainstem nuclei which regulate these autonomic functions are selectively vulnerable in PD [11]. These include the dorsal motor nucleus of the vagus, dorsal raphe nuclei, locus ceruleus and subceruleus and brainstem reticular formation.

Subtle motor signs are present before a definitive diagnosis of idiopathic PD is made $[12,13]$. At diagnosis, rest tremor is the most common presenting symptom of PD.[14] Charcot and Gowers both described ephemeral tremors preceding the onset of parkinsonism but this phenomenon has not been well described in the modern era $[15,16]$. Tremor has been identified in two studies as a prodromal sign of PD (in 
some cases up to 10 years prior to diagnosis) $[12,17]$ but whether these represent the well-documented relationship between essential tremor and PD $[18,19]$ or distinct prodromal parkinsonism is unclear. The pathogenesis of tremor is poorly understood and serotoninergic, dopaminergic, noradrenergic and cholinergic mechanisms may all contribute. Specific brainstem nuclei implicated in the generation of parkinsonian tremor include the locus ceruleus [20], ventral tegmental area [21], and dorsal raphe nuclei [22]. Stress and cognitive load can unmask tremor in PwP [23] and this may be mediated by the locus ceruleus via connections to the ventrolateral nucleus of the thalamus [20]. The ability of other activities to unmask parkinsonian tremor has not been well described to date. We present a series of patients who, in the prodromal phase of PD, experienced the emergence of tremor while yawning or straining at stool up to 20 years prior to their diagnosis. We present a hypothesis on how the early involvement of critical diencephalic and brainstem nuclei could lead to these previously unreported phenomena.

\section{Case Descriptions}

\section{Case 1}

A sixty year-old farmer presented with a twenty year history of intermittent right hand tremor which occurred initially only when yawning. His tremor became more persistent ten years later and he was referred to a neurologist five years subsequently when a rest tremor was noted. He had noticed fatigue and constipation 7-8 years prior to his diagnosis and had developed low mood and mild forgetfulness more recently. On examination, he had parkinsonian facies, rest tremor of his right hand which was re-emergent with sustained posture-holding, rigidity and bradykinesia which was greater on the right and a mildly stooped posture. He was initially prescribed levodopa/carbidopa to a dose of $300 \mathrm{mg} /$ day with no improvement in his tremor. He subsequently tried procyclidine at a dose of $5 \mathrm{mg}$ once daily initially. He did not tolerate this and is unsure if there was any tremor response. He switched back to levodopa/carbidopa and titrated to a dose of $600 \mathrm{mg} /$ day. There has been suboptimal improvement in his tremor but his overall course has been benign and he still remains independent and active 12 years after diagnosis. 


\section{Case 2}

A 75 year-old man, with a background of essential tremor since his thirties and lung transplant for idiopathic pulmonary fibrosis 3 years prior, was seen in follow-up in the movement disorder clinic complaining of worsening tremor over the previous year. Initially, this worsening was attributed to tacrolimus therapy. He was noted to have parkinsonian facies but no rigidity or bradykinesia. Whereas his longstanding tremor occurred exclusively with action, he reported that over the previous 3-4 years he experienced left hand tremor whenever he yawned. A DaTscan revealed moderate reduction in posterior striatal uptake more pronounced on the right. One year later he had slowed down and examination now revealed mild rigidity and bradykinesia, worse on the left, consistent with early idiopathic PD. He was commenced on levodopa/carbidopa $300 \mathrm{mg} /$ day which led to some tremor improvement. The patient died shortly after this but did not undergo autopsy.

\section{Case 3}

A 74 year-old right handed man presented with a three-year history of slowness of movement. His handwriting had become scrawling, his gait had become stooped and he had difficulty getting out of a car and turning in bed at night. More recently he had become anxious and forgetful. He had suffered from constipation for five years prior to the slowness of movement. Although he denied rest tremor, he reported that he developed tremor of his left leg whenever he strained at stool. His examination revealed hypomimia, bradyphrenia, asymmetric bradykinesia (more pronounced on the left hand side) but no obvious rest tremor. It was not possible to elicit a leg tremor in any position. He has been commenced on levodopa/carbidopa $300 \mathrm{mg} /$ day and awaits follow up.

\section{Case 4}

A sixty two year-old woman presented with a six-month history of difficulty spreading butter all over the surface of her toast, a reduction in the size and legibility of her handwriting and a tremor of the right middle finger at rest. Examination revealed right sided bradykinesia and cogwheel rigidity at the right wrist. She held her elbow flexed when walking and it swung less than the other side. Once the 
diagnosis of PD had been made she remembered that occasionally over the preceding ten years she had noticed that when she yawned her right hand had shaken for a few seconds but had not noticed this in the year prior to presentation. The patient subsequently died but did not undergo autopsy.

\section{Discussion}

We present a series of patients who, in the prodromal phase of PD, experienced the emergence of tremor initially only while yawning or straining at stool. Although at first glance, yawning and straining appear to have opposing physiological effects, the two processes are not entirely at odds with each other physiologically.

Studies have indicated that yawning leads to an increase in heart rate, lung volume and skin conductance and reduced venous return which may be mediated by mechanical stimulation of the carotid body $[24,25]$. The Valsalva maneuvre engages both sympathetic and parasympathetic pathways during four separate phases of the response [26]. Hemodynamic responses to the Valsalva maneuvre are well defined and also include an increase in heart rate and reduced venous return (mirroring those which occur during yawning ). This same physiological responses can also be stimulated by carotid sinus massage. This suggests that similar central autonomic activation may occur during both yawning and Valsalva maneuver during straining at stool [25]. The baroreceptor reflex described above activates a distributed central autonomic network which includes the supraoptic and paraventricular nuclei, posterior hypothalamus, paraventricular and dorsomedial hypothalamic nuclei, preoptic-anterior hypothalamic region, the periaqueductal gray, the central nucleus of the amygdala, and the insular cortex [27]. Of these, the area which may be of most interest in PD is the paraventricular nucleus of the hypothalamus, as outlined below.

\section{Yawning and the Paraventricular Nucleus of the Hypothalamus}

In order to understand how yawning could activate tremor in a patient with prodromal PD, the physiology of yawning must be considered. Yawning is a common physiological phenomenon occurring up to 20-30 times per day in healthy humans [28]. However, the pathophysiology of yawning is poorly understood, as is its role in neurological disease. Several hypotheses have been proposed as to why we yawn. 
These include regulation of arousal and sleep, thermoregulation, brain perfusion/oxygenation and a communicative/social tool [29].

The precise underlying neuroanatomical structures which mediate yawning are also unknown. Anencephalic infants yawn suggesting that the structures which execute the motor action of yawning reside in the brainstem [30]. Other lesion studies have localized this to near the reticular activating system [31]. It is clear that a number of structures modulate the yawning mechanism in a top-down fashion, most notably, the hypothalamic paraventricular nucleus (PVN) [28]. The PVN is located in the ventral diencephalon (Figure 1) and is composed of magnocellular neurons, parvocellular neurons and long-projecting neurons. These long-projecting neurons include oxytocinergic cells which project to the hippocampus, spinal cord and brainstem, including multiple autonomic brainstem nuclei (e.g. nucleus of the solitary tract, reticular formation, locus ceruleus, dorsal raphe nuclei and motor nucleus of the vagus). The proposed roles of the PVN are therefore wide-ranging from cardiovascular, gastrointestinal and respiratory homeostasis, through feeding and metabolism, to penile erections and sexual behavior [32,33].

\section{Yawning in Parkinson's Disease}

Yawning has been reported in parkinsonism as early as initial reports of encephalitis lethargica, both in acute and post-encephalitic stages [34]. However, its role in idiopathic PD is predominantly related to dopaminergic therapy. Goren \& Friedman first reported yawning as an aura signaling the levodopa-induced "on" period in two PwP [35]. Transient yawning preceded the clinical transition from "off" to "on" by approximately 5 minutes in a reproducible fashion. The authors hypothesized that dopaminergic and cholinergic mechanisms may be at play $[36,37]$. This letter prompted responses from other groups stating that the majority of PwP who are administered subcutaneous apomorphine (a direct D1/D2 dopamine receptor agonist) experience transient yawning coincident with onset of the motor response $[38,39]$ and in some patients, with transient penile erections [40]. Given that oxytocin release from the PVN mediates yawning and penile erections in rats following apomorphine administration, the PVN is assumed to play a similar role in 
apomorphine-induced yawning in these PWP $[33,41]$. The number of oxytocinergic neurons in the PVN is reduced (by over 20\%) in PwP [42]. The nuclear volume of the remaining neurons is increased suggesting a compensatory activation. This may result in altered sensitivity of these remaining neurons to dopaminergic stimulation. Initial studies examining ubiquitination suggested that Lewy bodies were not present in the PVN [42], however more recently alpha-synuclein immunohistochemistry has demonstrated that the PVN is directly involved, not only in confirmed PD cases but also in the incidental Lewy body disease group (Braak stage <=2) [43]. Importantly this suggests that Lewy body aggregation may occur in the PVN in the prodromal phase of PD.

Apomorphine injected into the PVN can induce yawning at concentrations 5-40 times lower than that required to induce yawning at the level of the striatum implying that the PVN is the primary site of action for dopaminergic yawning [44]. Furthermore, lesioning of the PVN and administration of oxytocin antagonists suppresses apomorphine-induced yawning $[41,45]$. D2-like antagonists do not suppress oxytocininduced yawning, suggesting that the dopaminergic effect is upstream from oxytocin $[46,47]$. Yawning induced by D2-agonists is suppressed by D2-like antagonists as expected. However, D2-agonist-induced yawning is also inhibited by anticholinergics $[35,48]$. Cholinesterase inhibitors and muscarinic receptor agonists can also induce yawning which can be suppressed by anticholinergics but not dopamine receptor antagonists $[36,48]$. Thus, the dopaminergic effect on yawning is likely executed by downstream cholinergic transmission, probably via M1 muscarinic receptors. In summary, the primary yawning mechanism is likely via oxytocinergic long-projecting neurons in the paraventricular nucleus enhancing cholinergic transmission in the hippocampus and multiple brainstem sites including the reticular formation (Figure 1).

\section{Defecation, Valsalva and Parkinson's Disease:}

Our fourth patient experienced prodromal emergence of tremor while straining at stool. Bowel dysfunction is a common prodromal feature of PD. During defecation in PwP, paradoxical sphincter contraction occurs, leading to significantly higher anal 
pressure than occurs in control subjects [49]. As a results, a greater rise in intraabdominal pressure is required for evacuation in PwP. Abdominal straining and hence, Valsalva can achieve this. The degree of paradoxical sphincter contraction on defecation is similar in early and late PD, indicating that this phenomenon is an early finding in PD and may even occur in the prodromal phase [50]. However, straining is impaired in PwP due to poorly coordinated glottal closure [51] and Valsalva maneuvers in PwP lead to a smaller increase in intraabdominal pressure compared with controls [52], suggesting a greater degree of straining is required for defecation in PwP. Furthermore, the vagal response to Valsalva maneuver is reduced in PwP, particularly in the setting of orthostatic hypotension (another prodromal PD syndrome) [53]. This implies abnormal and possibly aberrant vagal responses may occur during straining at stool and Valsalva maneuvers, even in the prodromal phase of PD.

The PVN, which densely innervates the dorsal vagal nuclei, clearly plays a central role in yawning but it may also play a crucial role in vagal control of gut motility. Stimulation of the PVN modulates the activity of gut-sensitive neurons in the vagal complex and may also modulate vago-vagal reflexes [54]. Excessive PVN activity may therefore be required to compensate for the deficient downstream regulation of defecation. Furthermore, vagal afferents can stimulate PVN neurons in the setting of changes in volume load as occurs during a Valsalva maneuvre [55]. In this way, straining at stool in PD could lead to similar activation of the PVN-brainstem axis as we have hypothesized occurs during yawning above. However, we have yet to discuss how either process could lead to the emergence of tremor in these patients.

\section{Unmasking Paradoxical Movement and Tremor:}

The striking feature of our cases is that they developed yawning- or strainingassociated rest tremor years before a diagnosis of PD was made. The emergence of tremor while yawning or straining at stool in PwP has not been previously described. However, involuntary movement occurring synchronously with yawning has been previously described wherein patients with acute hemiplegia may experience reflex elevation of the paralyzed arm during yawning [56-59]. This phenomenon of 
parakinesia brachialis oscitans has been reported in patients with vascular, demyelinating, infectious and degenerative lesions affecting the corticospinal tract, basal ganglia or brainstem and consists of reproducible involuntary elevation or abduction of the paretic limb coincident with jaw opening during yawning [59]. The paretic limb falls again when the yawn ends. The most common causes are lesions of the internal capsule and lentiform nucleus/caudate nucleus or pontomedullary lesions. The precise pathophysiology is unknown but it is hypothesized to occur as a reflex activity of brainstem structures when released from rostral inhibitory control, similar to the emergence of palatal tremor with uncontrolled activity of the olivary nucleus [59]. Walusinksi has presented a number of possible hypotheses for parakinesia brachialis oscitans $[29,56,59,60]$. Regulation of automatic respiratory activity such as diaphragmatic movement and stretching occurs via the coordinated activity of the pre-Botzinger complex in the ventral medulla and the adjacent lateral reticular nucleus (under modulatory control from the hypothalamus) $[61,62]$. The lateral reticular nucleus (LRN) plays a crucial role in integrating descending and ascending signals to regulate limb movements [63]. The fibers which project from the LRN to the deep cerebellar nuclei exert a direct excitatory effect on descending motor pathways via the reticulospinal and vestibulospinal tracts [63]. Even when corticospinal motor control is lost, the LRN continues to receive afferent stimulation from the ventral spinocerebellar tract. A strong afferent signal from contraction of respiratory muscles during yawning (or a strong Valsalva maneuver during straining at stool), could therefore lead to involuntary automatic limb movement through this spinoreticulocerebellar pathway [59].

Although parkinsonian tremor is a much more common phenomenon than parakinesia brachialis oscitans, its precise pathophysiology is equally poorly understood. Unlike rigidity and bradykinesia, parkinsonian tremor often takes longer to respond to dopaminergic therapy and some cases required higher doses [64]. Animal studies of selective dopaminergic basal ganglia lesions (e.g. MPTP) do not produce the characteristic parkinsonian tremor [65] and involvement of other brainstem areas such as the locus ceruleus or ventral tegmental area may be required to cause tremor [21]. Tremor severity is not related to nigral dopamine 
deficiency making dopamine unlikely to be the sole neurotransmitter involved in tremor generation. Serotoninergic deficits in midbrain raphe nuclei have been demonstrated with positron emission tomography (PET) and these correlate with tremor scores [22]. Importantly, the raphe nuclei receives input from the PVN. However, the effect of anticholinergic agents on parkinsonian tremor cannot be ignored. Antimuscarinic agents were the first pharmacological treatment for PD and still widely used for management of tremor. Neostriatal M4 muscarinic receptors have been implicated in generation of this tremor in rat models and tropicamide (which has a modest effect on M4 receptors) suppresses the tremor [66,67]. Multiple brainstem areas can be involved in generation of parkinsonian and non-parkinsonian tremor (including dentate-rubro-olivary pathways [68,69], dorsal raphe nuclei [70], bulbar reticular formation [71], nucleus ambiguous [72], locus ceruleus and ventral tegmental area [21]). Many of these regions receive projections from the PVN (Figure 1). In particular, the PVN projects to the reticular nuclei, raphe nuclei, ventral tegmental area, locus ceruleus and nucleus ambiguous [32].

Ephemeral tremors prior to the emergence of PD have been described by both Charcot and Gowers, however these were predominantly in the setting of acute stressors (emotional shock, prolonged anxiety, trauma or cold weather) $[15,16]$. Gowers noted that "the tremor subsides when the alarm is over" suggesting a brief physiological change may mediate these tremors. Trauma was noted to be the inciting cause in a number of cases, in particular trauma at the site in which tremor subsequently persisted. Although there may be a bias here (tremor in the traumatized limb being more notable than tremor elsewhere), it raises the possibility of sensory feedback modulating tremor thresholds. The spinoreticular pathway and brainstem reticular formation may play a role in parakinesia brachialis oscitans. However, this pathway is also involved in processing emotional response to pain [73]. Hence, the reticular formation may provide a common pathway to explain those tremors caused by emotional stress and those cause by physical trauma. Gowers also described the remarkable case of young lady, who when startled by water suddenly pouring onto her hand, developed tremor in that hand which subsequently spread, developing into typical PD. It is worth noting that in all of our cases, the tremor which 
occurred during yawning or straining was on the side in which persistent tremor eventually emerged. This supports the idea that our patients were displaying true prodromal parkinsonian tremor rather than an unrelated phenomenon.

Cognitive load is another common exacerbator of tremor. Dirkx and colleagues examined the effect of cognitive load on tremor in PwP using synchronous electromyography and functional MRI [20]. In a similar manner to what we observed, parkinsonian tremor can emerge or be amplified when patients experience a cognitive load such as being asked to carry out mental arithmetic under pressure in the consulting room. Dirkx and colleagues demonstrated that cognitive load correlated with tremor amplitude, pupillary diameter, heart rate and activity in the cognitive control network [20]. The authors hypothesized that cognitive load can increase tremor through a bottom-up noradrenergic ascending arousal system which activates the ventrolateral nucleus of the thalamus pars ventralis (VLpv) and hence the cerebellothalamocortical network driving tremor. Tremor-predominant PwP show less degeneration of the locus ceruleus than other PwP [74] and the locus ceruleus sends noradrenergic projections to the VLpv as well as other nodes of the cerebellothalamocortical network $[75,76]$. Dirkx and colleagues therefore concluded that the locus ceruleus mediates the increase in tremor amplitude, as well as the pupillary and heart rate changes. Since the PVN is a major sympathetic premotor nucleus of the pupillary reflex (via the intermediolateral column of spinal cord) [77] and modulates heart rate, it is possible that this nucleus may play a role in their findings. Given the dense connectivity between the PVN and the locus ceruleus, a similar activation of the cerebellothalamocortical network might enhance tremor during yawning or Valsalva while straining at stool in our patients.

Hence, it is possible that aberrant brainstem transmission during yawning or Valsalva maneouvre could activate the cerebellothalamocortical network either via the lateral reticular nucleus (and the deep cerebellar nuclei) or via the locus ceruleus (and the VLpv). The brainstem reticular formation and locus ceruleus have previously been implicated in the pathophysiology of RBD, the only well characterized prodromal syndrome in PD. 
Horsager et al. recently used the presence or absence of premotor RBD to dichotomize PD patients into "brain-first" and "body-first" subtypes [5]. Body-first patients demonstrate a wide range of abnormalities on functional imaging including cardiac denervation and cholinergic denervation of the colon. Given the widespread role of the PVN both in cardiovascular homeostasis as well as well as regulation of bowel function, it seems likely that the PVN may be involved in many of these "bodyfirst" patients.

Our hypothesis is speculative and future work is required to clarify the involvement of the PVN in prodromal PD and its clinical correlates. Only a single study to date has examined alpha-synuclein immunohistochemistry in the PVN. It is clear that welldesigned neuropathological studies examining the frequency and extent of involvement of the PVN in clinically well-characterised patients with PD (such as body-first subtypes) as well as patients with idiopathic RBD are needed. As we are on the threshold of diagnostic tests for the synucleinopathies, in particular with respect to Real-Time Quaking-Induced Conversion (RT-QuIC) in tissues such as skin and CSF, it may be able to test this hypothesis in vivo in patients such as those presented herein $[78,79]$. With potential disease modifying treatments in evolution, this may also have important implications in helping to define prodromal PD patients who may benefit from early treatment with such agents. Although the exact mechanisms underlying the emergence of tremor in prodromal PD are undefined, it clearly represents an important finding as it may help identify PwP at an earlier stage of disease than is currently possible. Vigilance for this phenomenon, for example in newly diagnosed PwP or in patients with idiopathic RBD, may lead to greater appreciation of its prevalence and the breadth of its spectrum.

\section{Conclusions}

The identification of a new clinical syndrome in prodromal PD has important implications for targeting early therapeutic interventions. The emergence of tremor coincident with yawning and straining at stool up to 20 years before a diagnosis of PD in our patients represents an important therapeutic window. A greater 
understanding of the pathophysiology of this phenomenon is required. The PVN likely plays a central role, either by increasing downstream cholinergic activity on critical brainstem nuclei such as the reticular formation, by stimulating the locus ceruleus to activate the cerebellothalamocortical network or by another autonomic mechanism. Aberrant cholinergic/noradrenergic transmission between these nondopaminergic brainstem nuclei early in PD could lead to tremor before the emergence of other (dopaminergic) parkinsonian signs, representing an early clinical clue to incipient PD.

\section{Documentation of Author Roles}

1) Research project: A. Conception, B. Organization, C. Execution;

2) Statistical Analysis: A. Design, B. Execution, C. Review and Critique;

3) Manuscript: A. Writing of the first draft, B. Review and Critique.

CF 1B, 1C, 3A

AJL 1A, 1B, 1C, 3B

JJM 3B

AM 3B

SS $1 B, 1 C, 3 B$

MF 3B

TL 1A, 3B

\section{Financial Disclosures (preceding 12 months)}

CF

\begin{tabular}{|l|l|}
\hline $\begin{array}{l}\text { Stock Ownership in medically-related } \\
\text { fields }\end{array}$ & None \\
\hline Intellectual Property Rights & None \\
\hline Consultancies & None \\
\hline Expert Testimony & None \\
\hline Advisory Boards & None \\
\hline Employment & None \\
\hline Partnerships & None \\
\hline Contracts & None \\
\hline Honoraria & None \\
\hline Royalties & None \\
\hline Grants & None \\
\hline Other & None \\
\hline
\end{tabular}

AJL 


\begin{tabular}{|l|l|}
\hline $\begin{array}{l}\text { Stock Ownership in medically-related } \\
\text { fields }\end{array}$ & None \\
\hline Intellectual Property Rights & None \\
\hline Consultancies & None \\
\hline Expert Testimony & None \\
\hline Advisory Boards & None \\
\hline Employment & None \\
\hline Partnerships & None \\
\hline Contracts & None \\
\hline Honoraria & None \\
\hline Royalties & None \\
\hline Grants & None \\
\hline Other & None \\
\hline
\end{tabular}

JJM

\begin{tabular}{|l|l|}
\hline $\begin{array}{l}\text { Stock Ownership in medically-related } \\
\text { fields }\end{array}$ & None \\
\hline Intellectual Property Rights & None \\
\hline Consultancies & None \\
\hline Expert Testimony & None \\
\hline Advisory Boards & None \\
\hline Employment & None \\
\hline Partnerships & None \\
\hline Contracts & None \\
\hline Honoraria & None \\
\hline Royalties & None \\
\hline Grants & None \\
\hline Other & None \\
\hline
\end{tabular}

AM

Stock Ownership in medically- None related fields

Intellectual Property Rights

None 


\begin{tabular}{|l|l|}
\hline Consultancies & None \\
\hline Expert Testimony & None \\
\hline Advisory Boards & None \\
\hline Employment & None \\
\hline Partnerships & None \\
\hline Contracts & None \\
\hline Honoraria & None \\
\hline Royalties & None \\
\hline Grants & None \\
\hline Other & None \\
\hline
\end{tabular}

SS

\begin{tabular}{|l|l|}
\hline $\begin{array}{l}\text { Stock Ownership in medically- } \\
\text { related fields }\end{array}$ & None \\
\hline Intellectual Property Rights & None \\
\hline Consultancies & None \\
\hline Expert Testimony & None \\
\hline Advisory Boards & None \\
\hline Employment & None \\
\hline Partnerships & None \\
\hline Contracts & None \\
\hline Honoraria & None \\
\hline Royalties & None \\
\hline Grants & None \\
\hline Other & None \\
\hline
\end{tabular}

MF

Stock Ownership in medically- None related fields 


\begin{tabular}{|l|l|}
\hline Intellectual Property Rights & None \\
\hline Consultancies & None \\
\hline Expert Testimony & None \\
\hline Advisory Boards & None \\
\hline Employment & None \\
\hline Partnerships & None \\
\hline Contracts & None \\
\hline Honoraria & None \\
\hline Royalties & None \\
\hline Grants & None \\
\hline Other & None \\
\hline
\end{tabular}

TL

\begin{tabular}{|l|l|}
\hline $\begin{array}{l}\text { Stock Ownership in medically- } \\
\text { related fields }\end{array}$ & None \\
\hline Intellectual Property Rights & None \\
\hline Consultancies & None \\
\hline Expert Testimony & None \\
\hline Advisory Boards & None \\
\hline Employment & None \\
\hline Partnerships & None \\
\hline Contracts & None \\
\hline Honoraria & None \\
\hline Royalties & None \\
\hline Grants & $\begin{array}{l}\text { Michael J Fox Foundation, Health Research } \\
\text { Board Ireland }\end{array}$ \\
\hline Other & None \\
\hline
\end{tabular}




\section{References:}

[1] Mahlknecht P, Seppi K, Poewe W (2015) The Concept of Prodromal Parkinson's Disease. J Parkinsons Dis 5, 681-697.

[2] Del Tredici K, Braak H (2012) Lewy pathology and neurodegeneration in premotor Parkinson's disease. Mov Disord 27, 597-607.

[3] Braak H, Del Tredici K, Bratzke H, Hamm-Clement J, Sandmann-Keil D, Rüb U (2002) Staging of the intracerebral inclusion body pathology associated with idiopathic Parkinson's disease (preclinical and clinical stages). $J$ Neurol 249 Suppl 3, III/1-5.

[4] Breen DP, Halliday GM, Lang AE (2019) Gut-brain axis and the spread of $\alpha$ synuclein pathology: Vagal highway or dead end? Mov Disord 34, 307-316.

[5] Horsager J, Andersen KB, Knudsen K, Skjærbæk C, Fedorova TD, Okkels N, Schaeffer E, Bonkat SK, Geday J, Otto M, Sommerauer M, Danielsen EH, Bech E, Kraft J, Munk OL, Hansen SD, Pavese N, Göder R, Brooks DJ, Berg D, Borghammer P (2020) Brain-first versus body-first Parkinson's disease: a multimodal imaging case-control study. Brain 143, 3077-3088.

[6] Palma J-A, Kaufmann H (2014) Autonomic disorders predicting Parkinson's disease. Parkinsonism Relat Disord 20 Suppl 1, S94-98.

[7] Berg D, Postuma RB, Adler CH, Bloem BR, Chan P, Dubois B, Gasser T, Goetz CG, Halliday G, Joseph L, Lang AE, Liepelt-Scarfone I, Litvan I, Marek K, Obeso J, Oertel W, Olanow CW, Poewe W, Stern M, Deuschl G (2015) MDS research criteria for prodromal Parkinson's disease. Mov Disord 30, 16001611.

[8] Dauvilliers Y, Schenck CH, Postuma RB, Iranzo A, Luppi P-H, Plazzi G, Montplaisir J, Boeve B (2018) REM sleep behaviour disorder. Nat Rev Dis Primers 4, 19.

[9] Kotagal V, Albin RL, Müller MLTM, Koeppe RA, Chervin RD, Frey KA, Bohnen NI (2012) Symptoms of rapid eye movement sleep behavior disorder are associated with cholinergic denervation in Parkinson disease. Annals of Neurology 71, 560-568.

[10] Fraigne JJ, Torontali ZA, Snow MB, Peever JH (2015) REM Sleep at its Core Circuits, Neurotransmitters, and Pathophysiology. Front Neurol 6, 123.

[11] Grinberg LT, Rueb U, Alho AT di L, Heinsen H (2010) Brainstem pathology and non-motor symptoms in PD. J Neurol Sci 289, 81-88.

[12] Alarcón F, Maldonado J-C, Cañizares M, Molina J, Noyce A, Lees AJ (2020) Motor Dysfunction as a Prodrome of Parkinson's Disease. Journal of Parkinson's Disease Preprint, 1-7.

[13] Lees AJ (1992) When did Ray Kennedy's Parkinson's disease begin? Mov Disord 7, 110-116.

[14] Hughes AJ, Daniel SE, Blankson S, Lees AJ (1993) A clinicopathologic study of 100 cases of Parkinson's disease. Arch Neurol 50, 140-148.

[15] Charcot JM (1889) Leçons du mardi à la Salpêtrière., Dehahaye et Lecrosnier, Paris.

[16] Gowers WR (William R (1888) A manual of diseases of the nervous system, Philadelphia : P. Blakiston, Son \& Co. 
[17] Schrag A, Horsfall L, Walters K, Noyce A, Petersen I (2015) Prediagnostic presentations of Parkinson's disease in primary care: a case-control study. The Lancet Neurology 14, 57-64.

[18] Tremor and other hyperkinetic movements (New York, N.Y.), Essential Tremor and Parkinson's Disease: Exploring the Relationship, Last updated September 1, 2019, Accessed on September 1, 2019.

[19] Thenganatt MA, Jankovic J (2016) The relationship between essential tremor and Parkinson's disease. Parkinsonism Relat Disord 22 Suppl 1, S162-165.

[20] Dirkx MF, Zach H, van Nuland AJ, Bloem BR, Toni I, Helmich RC (2020) Cognitive load amplifies Parkinson's tremor through excitatory network influences onto the thalamus. Brain.

[21] Tetrud JW, Langston JW (1992) Tremor in MPTP-induced parkinsonism. Neurology 42, 407-410.

[22] Doder M, Rabiner EA, Turjanski N, Lees AJ, Brooks DJ, 11C-WAY 100635 PET study (2003) Tremor in Parkinson's disease and serotonergic dysfunction: an 11C-WAY 100635 PET study. Neurology 60, 601-605.

[23] Lee HJ, Lee WW, Kim SK, Park H, Jeon HS, Kim HB, Jeon BS, Park KS (2016) Tremor frequency characteristics in Parkinson's disease under restingstate and stress-state conditions. J Neurol Sci 362, 272-277.

[24] Gupta S, Mittal S (2013) Yawning and its physiological significance. Int J Appl Basic Med Res 3, 11-15.

[25] Corey TP, Shoup-Knox ML, Gordis EB, Gallup GG (2012) Changes in Physiology before, during, and after Yawning. Front Evol Neurosci 3,.

[26] Srivastav S, Jamil RT, Zeltser R (2020) Valsalva Maneuver. In StatPearls StatPearls Publishing, Treasure Island (FL).

[27] Hilz MJ, Liu M, Koehn J, Wang R, Ammon F, Flanagan SR, Hösl KM (2016) Valsalva maneuver unveils central baroreflex dysfunction with altered blood pressure control in persons with a history of mild traumatic brain injury. BMC Neurology 16, 61.

[28] Walusinski 0 (2006) Yawning: unsuspected avenue for a better understanding of arousal and interoception. Med Hypotheses 67, 6-14.

[29] Teive HAG, Munhoz RP, Camargo CHF, Walusinski O (2018) Yawning in neurology: a review. Arq Neuropsiquiatr 76, 473-480.

[30] Heusner AP (1946) Yawning and associated phenomena. Physiol Rev 26, 156-168.

[31] Askenasy JJ (1989) Is yawning an arousal defense reflex? J Psychol 123, 609-621.

[32] Geerling JC, Shin J-W, Chimenti PC, Loewy AD (2010) Paraventricular hypothalamic nucleus: axonal projections to the brainstem. J Comp Neurol 518, 1460-1499.

[33] Argiolas A, Melis MR (2005) Central control of penile erection: role of the paraventricular nucleus of the hypothalamus. Prog Neurobiol 76, 1-21.

[34] Turner WA, Critchley M (1925) RESPIRATORY DISORDERS IN EPIDEMIC ENCEPHALITIS. Brain 48, 72-104.

[35] Goren JL, Friedman JH (1998) Yawning as an aura for an L-dopa-induced “on" in Parkinson's disease. Neurology 50, 823. 
[36] Protais P, Dubuc I, Costentin J (1983) Pharmacological characteristics of dopamine receptors involved in the dual effect of dopamine agonists on yawning behaviour in rats. Eur J Pharmacol 94, 271-280.

[37] Zarrindast MR, Fatehi F, Mohagheghi-Badi M (1995) Effects of adenosine agents on apomorphine-induced yawning in rats. Psychopharmacology (Berl) 122, 292-296.

[38] O’Sullivan JD, Lees AJ, Hughes AJ (1999) Yawning in Parkinson's disease. Neurology 52, 428.

[39] Colosimo C, Pontieri FE (1999) Yawning in Parkinson's disease. Neurology $52,428$.

[40] O'Sullivan JD, Hughes AJ (1998) Apomorphine-induced penile erections in Parkinson's disease. Mov Disord 13, 536-539.

[41] Argiolas A, Melis MR, Mauri A, Gessa GL (1987) Paraventricular nucleus lesion prevents yawning and penile erection induced by apomorphine and oxytocin but not by ACTH in rats. Brain Res 421, 349-352.

[42] Purba JS, Hofman MA, Swaab DF (1994) Decreased number of oxytocinimmunoreactive neurons in the paraventricular nucleus of the hypothalamus in Parkinson's disease. Neurology 44, 84-89.

[43] De Pablo-Fernandez E, Courtney R, Holton JL, Warner TT (2017) Hypothalamic $\alpha$-synuclein and its relation to weight loss and autonomic symptoms in Parkinson's disease. Mov Disord 32, 296-298.

[44] Melis MR, Argiolas A, Gessa GL (1987) Apomorphine-induced penile erection and yawning: site of action in brain. Brain Res 415, 98-104.

[45] Melis MR, Argiolas A, Gessa GL (1989) Evidence that apomorphine induces penile erection and yawning by releasing oxytocin in the central nervous system. Eur J Pharmacol 164, 565-570.

[46] Melis MR, Argiolas A, Gessa GL (1986) Oxytocin-induced penile erection and yawning: site of action in the brain. Brain Res 398, 259-265.

[47] Argiolas A, Melis MR, Gessa GL (1988) Yawning and penile erection: central dopamine-oxytocin-adrenocorticotropin connection. Ann N Y Acad Sci 525, 330-337.

[48] Collins GT, Eguibar JR (2010) Neurophamacology of yawning. Front Neurol Neurosci 28, 90-106.

[49] Sakakibara R, Kishi M, Ogawa E, Tateno F, Uchiyama T, Yamamoto T, Yamanishi T (2011) Bladder, bowel, and sexual dysfunction in Parkinson's disease. Parkinsons Dis 2011, 924605.

[50] Bassotti G, Maggio D, Battaglia E, Giulietti O, Spinozzi F, Reboldi G, Serra AM, Emanuelli G, Chiarioni G (2000) Manometric investigation of anorectal function in early and late stage Parkinson's disease. J Neurol Neurosurg Psychiatry 68, 768-770.

[51] Fontana GA, Pantaleo T, Lavorini F, Benvenuti F, Gangemi S (1998) Defective motor control of coughing in Parkinson's disease. Am J Respir Crit Care Med 158, 458-464.

[52] Mathers SE, Kempster PA, Law PJ, Frankel JP, Bartram CI, Lees AJ, Stern GM, Swash M (1989) Anal sphincter dysfunction in Parkinson's disease. Arch Neurol 46, 1061-1064.

[53] Goldstein DS, Eldadah BA, Holmes C, Pechnik S, Moak J, Saleem A, Sharabi Y (2005) Neurocirculatory abnormalities in Parkinson disease with 
orthostatic hypotension: independence from levodopa treatment. Hypertension 46, 1333-1339.

[54] Zhang X, Fogel R, Renehan WE (1999) Stimulation of the paraventricular nucleus modulates the activity of gut-sensitive neurons in the vagal complex. Am J Physiol 277, G79-90.

[55] Coote JH (1995) Cardiovascular function of the paraventricular nucleus of the hypothalamus. Biol Signals 4, 142-149.

[56] Walusinski O, Quoirin E, Neau J-P (2005) [Parakinesia brachialis oscitans]. Rev Neurol (Paris) 161, 193-200.

[57] Farah M, Barcellos I, Boschetti G, Munhoz RP (2015) Parakinesia Brachialis Oscitans: A Case Report. Mov Disord Clin Pract 2, 436-437.

[58] de Lima PMG, Munhoz RP, Becker N, Teive HAG (2012) Parakinesia brachialis oscitans: report of three cases. Parkinsonism Relat Disord 18, 204-206.

[59] Walusinski O, Neau J-P, Bogousslavsky J (2010) Hand up! Yawn and raise your arm. Int J Stroke 5, 21-27.

[60] Walusinski O (2014) How yawning switches the default-mode network to the attentional network by activating the cerebrospinal fluid flow. Clin Anat 27, 201-209.

[61] Ezure K, Tanaka I (1997) Convergence of central respiratory and locomotor rhythms onto single neurons of the lateral reticular nucleus. Exp Brain Res 113, 230-242.

[62] Schomburg ED, Steffens H, Dembowsky K (2003) Rhythmic phrenic, intercostal and sympathetic activity in relation to limb and trunk motor activity in spinal cats. Neurosci Res 46, 229-240.

[63] Alstermark B, Ekerot C-F (2015) The lateral reticular nucleus; integration of descending and ascending systems regulating voluntary forelimb movements. Front Comput Neurosci 9,.

[64] Hallett M (2012) Parkinson's disease tremor: pathophysiology. Parkinsonism Relat Disord 18 Suppl 1, S85-86.

[65] DeLong MR (1990) Primate models of movement disorders of basal ganglia origin. Trends Neurosci 13, 281-285.

[66] Betz AJ, McLaughlin PJ, Burgos M, Weber SM, Salamone JD (2007) The muscarinic receptor antagonist tropicamide suppresses tremulous jaw movements in a rodent model of parkinsonian tremor: possible role of M4 receptors. Psychopharmacology (Berl) 194, 347-359.

[67] Salamone JD, Correa M, Carlson BB, Wisniecki A, Mayorga AJ, Nisenbaum E, Nisenbaum L, Felder C (2001) Neostriatal muscarinic receptor subtypes involved in the generation of tremulous jaw movements in rodents implications for cholinergic involvement in parkinsonism. Life Sci 68, 2579-2584.

[68] Raina GB, Cersosimo MG, Folgar SS, Giugni JC, Calandra C, Paviolo JP, Tkachuk VA, Zuñiga Ramirez C, Tschopp AL, Calvo DS, Pellene LA, Uribe Roca MC, Velez M, Giannaula RJ, Fernandez Pardal MM, Micheli FE (2016) Holmes tremor: Clinical description, lesion localization, and treatment in a series of 29 cases. Neurology 86, 931-938.

[69] Vidailhet M, Jedynak CP, Pollak P, Agid Y (1998) Pathology of symptomatic tremors. Mov Disord 13 Suppl 3, 49-54. 
[70] Costall B, Kelly DM, Naylor RJ (1976) The importance of 5hydroxytryptamine for the induction of harmine tremor and its antagonism by dopaminergic agonists assessed by lesions of the midbrain raphe nuclei. Eur J Pharmacol 35, 109-119.

[71] Jenkner FL, Ward A (1953) Bulbar reticular formation and tremor. AMA Arch Neurol Psychiatry 70, 489-502.

[72] Batini C, Buisseret-Delmas C, Conrath-Verrier M (1981) Harmaline-induced tremor. I. Regional metabolic activity as revealed by [14C]2-deoxyglucose in cat. Exp Brain Res 42, 371-382.

[73] Martins I, Tavares I (2017) Reticular Formation and Pain: The Past and the Future. Front Neuroanat 11,.

[74] Paulus W, Jellinger K (1991) The neuropathologic basis of different clinical subgroups of Parkinson's disease. J Neuropathol Exp Neurol 50, 743-755.

[75] McCormick DA, Pape HC, Williamson A (1991) Actions of norepinephrine in the cerebral cortex and thalamus: implications for function of the central noradrenergic system. Prog Brain Res 88, 293-305.

[76] Samuels ER, Szabadi E (2008) Functional neuroanatomy of the noradrenergic locus coeruleus: its roles in the regulation of arousal and autonomic function part II: physiological and pharmacological manipulations and pathological alterations of locus coeruleus activity in humans. Curr Neuropharmacol 6, 254-285.

[77] Szabadi E (2018) Functional Organization of the Sympathetic Pathways Controlling the Pupil: Light-Inhibited and Light-Stimulated Pathways. Front Neurol 9, 1069.

[78] Rossi M, Candelise N, Baiardi S, Capellari S, Giannini G, Orrù CD, Antelmi E, Mammana A, Hughson AG, Calandra-Buonaura G, Ladogana A, Plazzi G, Cortelli P, Caughey B, Parchi P (2020) Ultrasensitive RT-QuIC assay with high sensitivity and specificity for Lewy body-associated synucleinopathies. Acta Neuropathol 140, 49-62.

[79] Wang Z, Becker K, Donadio V, Siedlak S, Yuan J, Rezaee M, Incensi A, Kuzkina A, Orrú CD, Tatsuoka C, Liguori R, Gunzler SA, Caughey B, JimenezCapdeville ME, Zhu X, Doppler K, Cui L, Chen SG, Ma J, Zou W-Q (2020) Skin $\alpha$-Synuclein Aggregation Seeding Activity as a Novel Biomarker for Parkinson Disease. JAMA Neurol. 


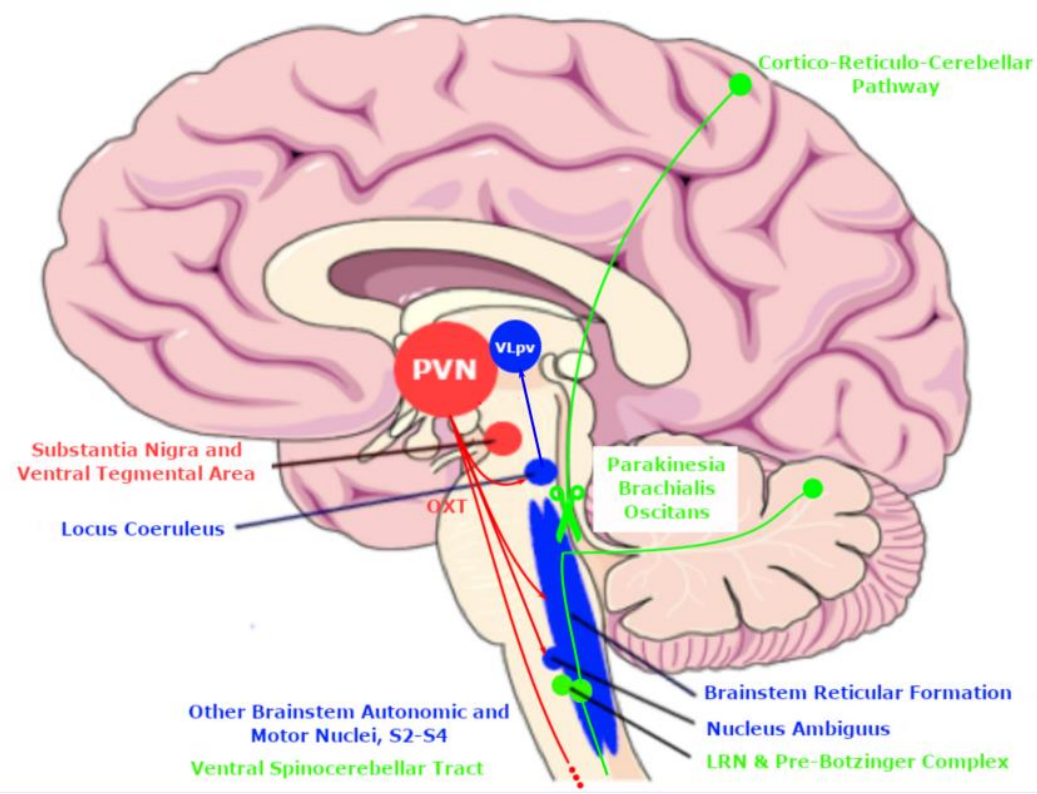

Figure Legend:

Figure 1. Cartoon showing afferent and efferent projections of the paraventricular nucleus (PVN) salient to yawning (red), tremor (blue) and parakinesia brachialis oscitans (green). DA: dopamine; LRN: Lateral reticular nucleus, OXT: oxytocin; VLpv: ventrolateral nucleus of the thalamus pars ventralis. 